\title{
High-strength opioid formulations: the case for a ministerial recall
}

\author{
Matthew Herder JSM LLM, David Juurlink MD PhD
}

— Cite as: CMAJ 2018 December 3;190:E1404-5. doi: 10.1503/cmaj.181289

CMAJ Podcasts: author interview at https://soundcloud.com/cmajpodcasts/181289-com

$\mathbf{U}$ ntil recently, the power to recall pharmaceuticals from the market was absent from Canadian law. In November 2014, this deficiency was remedied with the passage of the Protecting Canadians from Unsafe Drugs Act, ${ }^{1}$ widely known as Vanessa's Law, which empowers the minister of health to recall a drug when he or she "believes that a therapeutic product presents a serious or imminent risk of injury to health." ${ }^{1}$ We contend that a strong case can be made for recall from the Canadian market of high-dose opioid formulations: those containing $100 \mathrm{mg}$ of morphine, $80 \mathrm{mg}$ of oxycodone or $20 \mathrm{mg}$ or more of hydromorphone, and fentanyl patches releasing 75 or $100 \mu \mathrm{g}$ per hour. We explain why the legal requirements of section 21.3(1) of this act are met and highlight challenges to exercising this regulatory power responsibly.

In the early 1960s, thalidomide remained on the Canadian market even after its profound teratogenicity became apparent. ${ }^{2}$ After initially downplaying the harms of the drug, Canada's Food and Drug Directorate eventually had to negotiate a voluntary withdrawal by the manufacturer in March 1962, 3 months after its withdrawal elsewhere. Lacking the legal authority to recall the drug from the market unilaterally, the Parliament of Canada finally prohibited its sale in December 1962, in an effort to eliminate thalidomide from pharmacy shelves. ${ }^{3}$

The issue now is not whether a drug can be recalled but rather under what circumstances that power should be exercised. In fact, section 21.3(1) of Vanessa's Law sets a relatively low threshold. Rather than requiring scientific certainty, the minister of health must simply believe a serious or imminent health risk exists. ${ }^{4}$ Courts have determined that the minister's belief must simply be supported by "some evidence." Importantly, the minister need not consult with a drug's manufacturer to arrive at this opinion. Although Health Canada maintains that the manufacturer should be afforded a "reasonable opportunity to respond" before issuing a recall, public safety takes priority. At present, there is good evidence for the minister to believe that highstrength opioid formulations constitute a risk to public health.

Section 21.3(1) does not require a risk to be both serious and imminent for a recall to be issued. In crafting Vanessa's Law, Parliament recognized that therapeutic products may carry serious,

\section{KEY POINTS}

- The federal minister of health has the power, under the Food and Drugs Act, to recall a drug from the Canadian market when the minister believes a serious or imminent risk of injury to health exists; that legal threshold is met in the case of highstrength opioid formulations.

- High-strength opioid products (which gained regulatory approval despite a lack of evidence supporting their use) afford the equivalent of between 200 and 400 mg of morphine per day, likely resulting in net harm to most patients.

- The continued availability of these products normalizes an outdated and dangerous practice not supported by current prescribing guidelines.

- The potential unintended consequences of a recall can be mitigated for patients currently receiving high daily doses simply by substituting an equivalent dose of lower-strength products.

even devastating risks and, accordingly, set a lower threshold for using the recall power than, for example, that required of a physician before breaching patient confidentiality to avoid harm to a third party where the harm must be both serious and imminent. ${ }^{6}$ Although the Food and Drugs Act does not define "serious risk," Health Canada indicates that this determination is made on a case-by-case basis in view of several considerations, including the seriousness of the adverse health consequence, the vulnerability of the patient population exposed to the drug and the extent of the population's exposure to the product. ${ }^{4}$ Highstrength opioid formulations raise each of these considerations.

The potential harms of high-strength opioid formulations include accidental death by overdose, as well as falls, fractures, cognitive impairment, testosterone suppression, depression, paradoxical worsening of pain, motor vehicle collisions and physical dependence. These harms are both serious and dose related, ${ }^{7-9}$ and evidence-based guidelines now exhort physicians not to escalate doses beyond $90 \mathrm{mg}$ of morphine or equivalent (MME) per day when treating chronic pain. Above this threshold, it is likely that opioids are, on balance, harming more than helping, even when behavioural aspects of addiction are not present. ${ }^{9}$ The high-strength 
formulations covered under our proposal, which were approved for the treatment of chronic pain, yield about 200 to 400 MME per day when used as intended. We are unaware of any published evidence that shows that dosing of this sort to afford more benefit than harm; indeed, current guidelines strongly discourage daily doses exceeding 90 MME because net harm is likely. ${ }^{10}$ The availability of these products normalizes a dangerous practice that current guidelines actively discourage. Indeed, their removal from market today is not conceptually different from Purdue Pharma's voluntary removal of OxyContin (160 mg formulation) in 2001.

Furthermore, the vulnerability of patients taking highstrength opioids is concerning. These patients have escalated to high doses over time because of the progressive failure of lower doses, reflecting tolerance. Few can simply stop therapy without experiencing opioid withdrawal - a severe and often protracted syndrome characterized by pain, impaired function, insomnia, negative effects on mood and sometimes even suicidality. These effects resolve when opioids are resumed, reinforcing the perception of effectiveness and ongoing need. Put simply, high-dose opioids constitute a self-perpetuating therapy, with patients left vulnerable by the need for ongoing treatment to avoid withdrawal, itself a pernicious drug-related harm.

Finally, the prescribing of high-strength opioid formulations remains widespread, with more than 30 million such products dispensed in Canada each year, despite recommendations against the practice. ${ }^{11}$

The legal requirements of section 21.3(1) are clearly met. The minister may nevertheless fear a recall's unintended consequences. The primary concern is that removal of high-strength opioid formulations from the Canadian market may lead to abrupt tapering of opioids in patients who are receiving treatment by physicians who do not appreciate the potentially serious consequences of opioid withdrawal. This risk can be mitigated for a given patient by substituting an equivalent dose of lower-strength products - for example, 2 fentanyl patches (each with a dosage of $50 \mu \mathrm{g}$ per hour) instead of 1 patch with a dosage of $100 \mu \mathrm{g}$ per hour. This will afford the same daily dose, while also providing an opportunity to discuss the merits of gradual tapering with individual patients on a case-by-case basis.

A second concern relates to the concept of "pill burden" - the prospect, for example, of taking four 40-mg oxycodone tablets per day rather than two $80 \mathrm{mg}$ tablets, or applying 2 fentanyl patches rather than 1 . This relatively minor inconvenience would be far out- weighed by the societal benefit resulting from market removal of formulations that, by their very nature, perpetuate an antiquated and dangerous practice.

In 2016, the federal minister of health stated that "all tools are on the table" to address the opioid crisis. ${ }^{12}$ There is little sign that the crisis is abating in Canada. Ministerial recall of the most hazardous opioid formulations is a powerful regulatory tool that should be deployed to address one aspect of the crisis: the excessive prescribing of opioids for chronic pain. Timely information sharing among health professionals and government agencies can help guard against the potential unintended consequences of a recall. However, coupling new prescribing guidelines that help regulate the profession with a federal recall of high-strength formulations would go a long way to alter dangerous prescribing practices that have helped to fuel this crisis. ${ }^{13}$ We call on current federal Minister of Health, Hon. Ginette Petitpas Taylor, to exercise the authority granted to her under Vanessa's Law and remove high-strength opioid formulations from the Canadian market.

\section{References}

1. Protecting Canadians from Unsafe Drugs Act (Vanessa's Law), S.C. 2014, c. 24.

2. Webb JF. Canadian thalidomide experience. Can Med Assoc J 1963;89:987-92.

3. An Act to Amend the Food and Drugs Act, S.C. 1962, c. 15.

4. Amendments to the Food and Drugs Act: guide to new authorities (power to require \& disclose information, power to order a label change and power to order a recall). Ottawa: Health Canada; 2015. Available: www.hc-sc.gc.ca/dhp-mps/ legislation/unsafedrugs-droguesdangereuses-amendments-modifications-eng. php (accessed 2016 Nov. 14).

5. Miel Labonte Inc. v. Canada (Attorney General), 2006 FC 195.

6. Tarasoff $v$. Regents of the University of California, 17 Cal. 3d 425, 551 P.2d 334 (Cal. 1975).

7. Gomes T, Juurlink DN, Dhalla IA, et al. Trends in opioid use and dosing among socio-economically disadvantaged patients. Open Med 2011;5:e13-22.

8. Bohnert ASB, Valenstein M, Bair MJ, et al. Association between opioid prescribing patterns and opioid overdose-related deaths. JAMA 2011;305:1315-21.

9. Juurlink DN. Rethinking "doing well” on chronic opioid therapy. CMAJ 2017;189: E1222-3.

10. Busse JW, Craigie S, Juurlink DN, et al. Guidelines for opioid therapy and chronic noncancer pain. CMAJ 2017;189:E659-66.

11. Gomes T, Mamdani MM, Paterson MJ, et al. Trends in high-dose opioid prescribing in Canada. Can Fam Physician 2014;60:826-32.

12. Howlett K. Jane Philpott promises use of "all tools" in opioid crisis. The Globe and Mail [Toronto]. 2016 Nov. 18 [updated 2017 Apr. 7]. Available: www. theglobeandmail.com/news/national/medical-experts-urge-ottawa-to-declare -public-emergency-over-opioid-crisis/article32926287/(accessed 2016 Nov. 24).

13. Gomes T, Khuu W, Martins D, et al. Contributions of prescribed and non-prescribed opioids to opioid related deaths: population-based cohort study in Ontario, Canada. BMJ 2018;362:k3207.
Competing interests: Matthew Herder received a research grant from the Canadian Institutes of Health Research (CIHR) during the conduct of this study. He is a member of the Patented Medicines Prices Review Board. David Juurlink has received research grants from the Ontario Drug Policy Research Network and CIHR, as well as payment for a medicolegal opinion from Dutton Brock and lecture fees from Samford University, the University of Massachusetts, Dalhousie University and the University of Calgary, outside of the submitted work. He is an unpaid member of Physicians for Responsible Opioid Prescribing and a member of the American College of Medical Toxicology. No other competing interests were declared.

This article has been peer reviewed.
Affiliations: Health Law Institute and Department of Pharmacology, Faculty of Medicine (Herder), Dalhousie University, Halifax, NS; Division of Clinical Pharmacology and Toxicology, and Medicine, Pediatrics, and Health Policy, Management and Evaluation (Juurlink), University of Toronto; Divisions of General Internal Medicine and Clinical Pharmacology \& Toxicology (Juurlink), Sunnybrook Health Sciences Centre, Toronto, Ont.

Contributors: David Juurlink conceived of the focus of the commentary and Matthew Herder prepared the first draft. Both authors contributed equally to the research, analysis and writing of this manuscript; revised it critically for important intellectual content; gave final approval of the version to be published; and agreed to be accountable for all aspects of the work.

Correspondence to: Matthew Herder, Matthew.Herder@Dal.ca 